\title{
Effect of Cd on Microstructure and Dry Sliding Wear Behavior of (Al-12\%Si) Alloy
}

\author{
Muna K. Abbass \\ Department of Production Engineering and Metallurgy, University of Technology, Baghdad, Iraq \\ Received 10 May 2008; accepted 1 April 2009 \\ تأثير الكادميوم على التركيب المجهري و سلوك البلى الانزلاقي الجاف لسبيكة (Al-12\%Si) \\ هنى خفير عباس

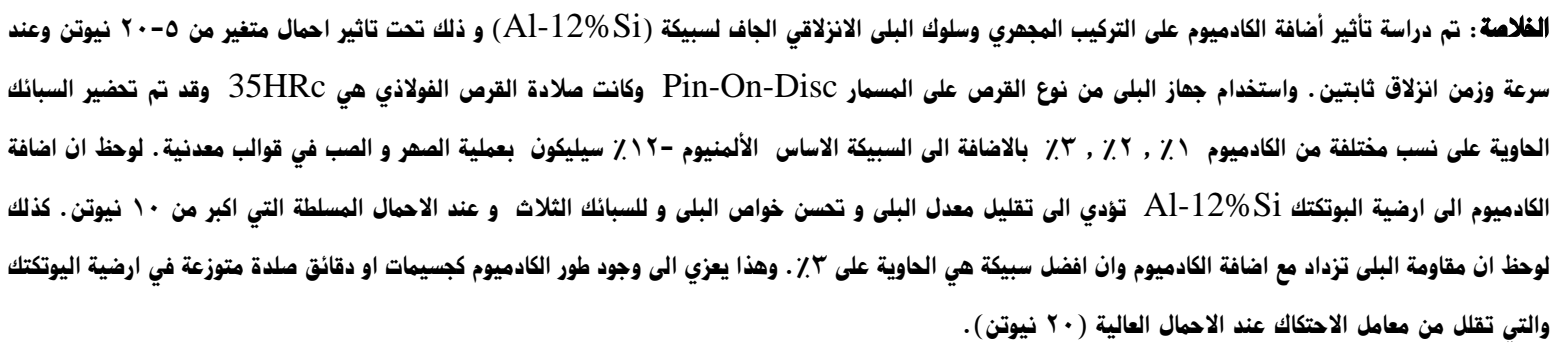

الهنزداه الهنتاهية: مقاومة التأكل ، سيليكون، الالمنيوم ، سبيكة، معدن الكادميم، معامل الاحتكاك.

\begin{abstract}
The aim of the present research is to study the effect of cadmium addition on microstructure and wear behavior of the alloy (Al-12\%Si) under dry sliding conditions. Wear behavior was studied by using the Pin-OnDisc technique under different conditions at applied loads 5-20 N, at constant sliding speed and in constant time. The steel disc hardness was 35HRc. All alloys were prepared with different percentages of cadmium (1.0, 2.0, 3.0) wt $\%$. Also the base alloy was prepared by melting and pouring the molten metal in a metallic mold. It was found that the cadmium addition to Al-Si matrix decreases the wear rate and improves the wear properties for alloys containing -Cd under loads above $10 \mathrm{~N}$. It was also found that the alloy Al-12\%Si containing 3\%Cd is the best alloy in wear resistance and friction coefficient. This is due to presence of the Cd-phase as cuboids or hard particles distributed in a eutectic matrix which reduces the friction coefficient at high loads (20N).
\end{abstract}

Keywords: Wear resistance, Al-Si alloy, Cadmium, Friction coefficient

\section{Introduction}

Wear may be defined as the progressive loss of a substance from the operating surface of a body occurring as a result of relative motion of the surface with respect to another body (Stan Grainger, 1994). The concept embraces metal to metal, metal to other solids and metal to fluid contact. This definition is clearly associated with the surfaces of materials. It must be recognized that wear and friction are not intrinsic properties of a material but are characteristic of the total engineering system and its operating environment Any change in stress, temperature, speed can have a significant effect on the type of wear or the wear-rate of a component (Askwith, 1980). Aluminum-Silicon (Al-Si) castings are considered the most commercially used (Bolten, 1998 and Mustafa 1995), because of their engineering significance accepted mechanical properties, good corrosion resistance, rela-

\footnotetext{
* Corresponding author’s e-mail: mukeab2005@yahoo.com
}

tively low thermal expansion coefficient and high fluidityduring melting and casting (Bolten, 1998). Therefore these alloys are often used in many tri-bological and bearing applications, pistons, cylinder heads in combustion chamber zones, camshaft bearings, spark plug bosses and bolt bosses (Dana, 2001). There are three families of aluminum-based bearing alloys in common use. They are Al$\mathrm{Pb}, \mathrm{Al}-\mathrm{Sn}$ and $\mathrm{Al}-\mathrm{Si}-\mathrm{Cd}$. Cadmium is used in bearing alloys, due to a low coefficient of friction and very good fatigue resistance.

Abbas and Ibrahim (2003) studied the effect of $\mathrm{Cu}$ and $\mathrm{Mg}$ adding on wear behavior of (Al-8\%Si) under dry sliding conditions and they concluded that the hardness and wear resistance increase because of formations of hard second-phase particles such as $\mathrm{Al}_{2} \mathrm{Cu}(\theta)$ and CuMgAl. Israa (2005) studied the effect of lead addition on sliding wear resistance and friction coefficient of Al-16\%Si alloy 


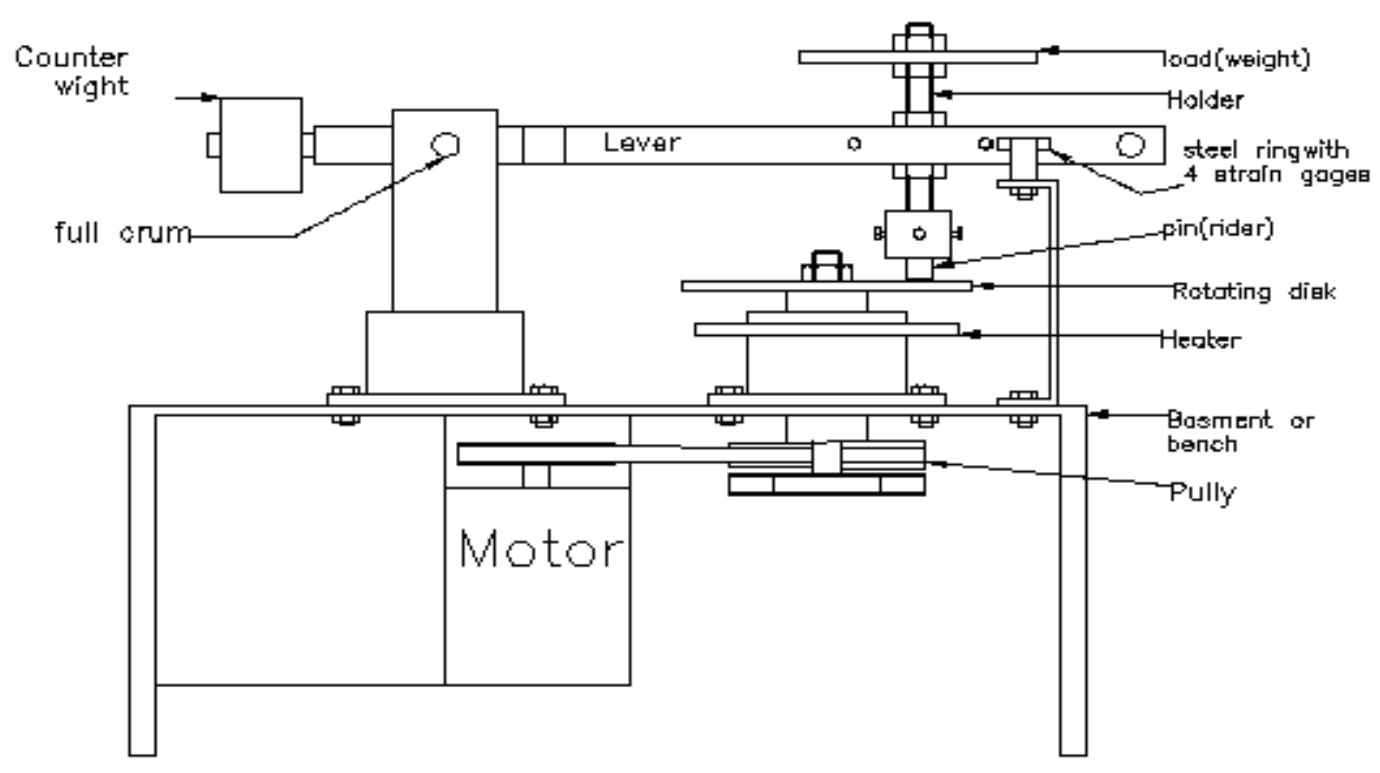

Figure 1. The Pin-On-Disc wear appratus

under varying loads and sliding speed conditions. She concluded that the wear rate of an alloy increases with speed and applied load. It has been observed that the wear rate and friction coefficient decrease noticeably with increasing $w t \%$ of lead. The influence of calcium on the microstructure and properties of an $\mathrm{Al}-7 \% \mathrm{Si}-0.3 \% \mathrm{Mg}-$ $\mathrm{xFe}$ alloy has been studied by Sreeja Kumarl, et al. (2006), who concluded that the addition of calcium modifies the eutectic microstructure and also reduces the size of intermetallic Fe-platelets, causing improved ductility and impact strength.

Basavakumar, et al. (2007) studied the microstructures and dry sliding wear behavior of $\mathrm{Al}-7 \mathrm{Si}$ and $\mathrm{Al}-7 \mathrm{Si}-2.5 \mathrm{Cu}$ cast alloys after various melt treatments like grain refinement and modification. Results indicate that the combined grain refined and modified Al-7Si-2.5Cu cast alloys which have microstructures consisting of uniformly distributed $\alpha$-Al grains, eutectic $\mathrm{Al}$-silicon and fine $\mathrm{CuAl}_{2}$ particles in the interdendritic region. These alloys exhibited better wear resistance in the cast condition compared with the same alloy subjected to only grain refinement or modification.

The aim of present work was to study the effect of cadmium addition on the wear rate and friction coefficient of $\mathrm{Al}-12 \% \mathrm{Si}$ alloy under dry sliding conditions.

\section{Experimental Work}

\subsection{Specimens Preparation}

The Al-12\%Si alloy (base alloy) was melted and different percentages of cadmium (1.0, 2.0, and 3.0) wt\% were added to the melt of $\mathrm{Al}-\mathrm{Si}$ separately. Cadmium metal was enveloped with aluminum foil before being added to the melt. For each experiment about $300 \mathrm{gm}$ of prealloyed $(\mathrm{Al}-12 \% \mathrm{Si})$ in alumina crucible was placed in an electric resistance furnace at a temperature $700^{\circ} \mathrm{C}$ which is below the boiling temperature of cadmium metal $\mathrm{Tp}=767^{\circ} \mathrm{C}$. A small amount of flux $\left(2 \% \mathrm{CaF}_{2}\right)$ was added to the melt to remove the impurities (as slag) from the melt. The melt was poured into a metallic mold which was dried before the casting operation at $120^{\circ} \mathrm{C}$ by using the Heracus drier type. The castings were left to cool down in the air. The specimens of prepared alloys had $100 \mathrm{~mm}$ length and $13 \mathrm{~mm}$ diameter.

\subsection{XRD Measurement}

The X-Ray diffraction measurements have been carried out using Shimadzu-labx X-ray diffraction unit model XRD-6000, $\mathrm{kV}=40, \mathrm{Cu} \mathrm{k} \alpha$, and XRF (EDXRF) type, Twin-X, Oxford co. England. These measurements include; base alloy and the Al-12\%Si$3 \% \mathrm{Cd}$ alloy to identify and estimate of the phases in an alloy.

\subsection{Wear Specimens}

Wear specimens were machined from an ingot and cut according to ASTM specification D2625-83 to 20mm length and 10mm diameter (ASTM, 1989). Then one surface of each specimen was ground by using emery paper of SiC in different grits (220,320,500 and 1000). The polishing was applied to the specimens by using diamond paste of size $1.0 \mu \mathrm{m}$ with a special polishing cloth and lubricant to obtain a clean and smooth surface. The initial surface roughness of the wear pins was $\mathrm{Ra}=0.20 \mu \mathrm{m}$.

\subsection{Wear Apparatus}

A Pin-On-Disc wear apparatus was used, which was designed according to ASTM specification F732-82 (ASTM, 1989) as shown in Fig. 1. The pin (specimen) was fixed and the disc (carbon steel) was rotating at a speed of $510 \mathrm{rpm}$. The tangential force (friction force) was rotating between the pin and the disc through their interface sliding. The main features of the test specimens and loading system are described below.

\subsection{Test Specimen and Loading System}

The test specimen and loading system shown in Fig. 1 consist of: 


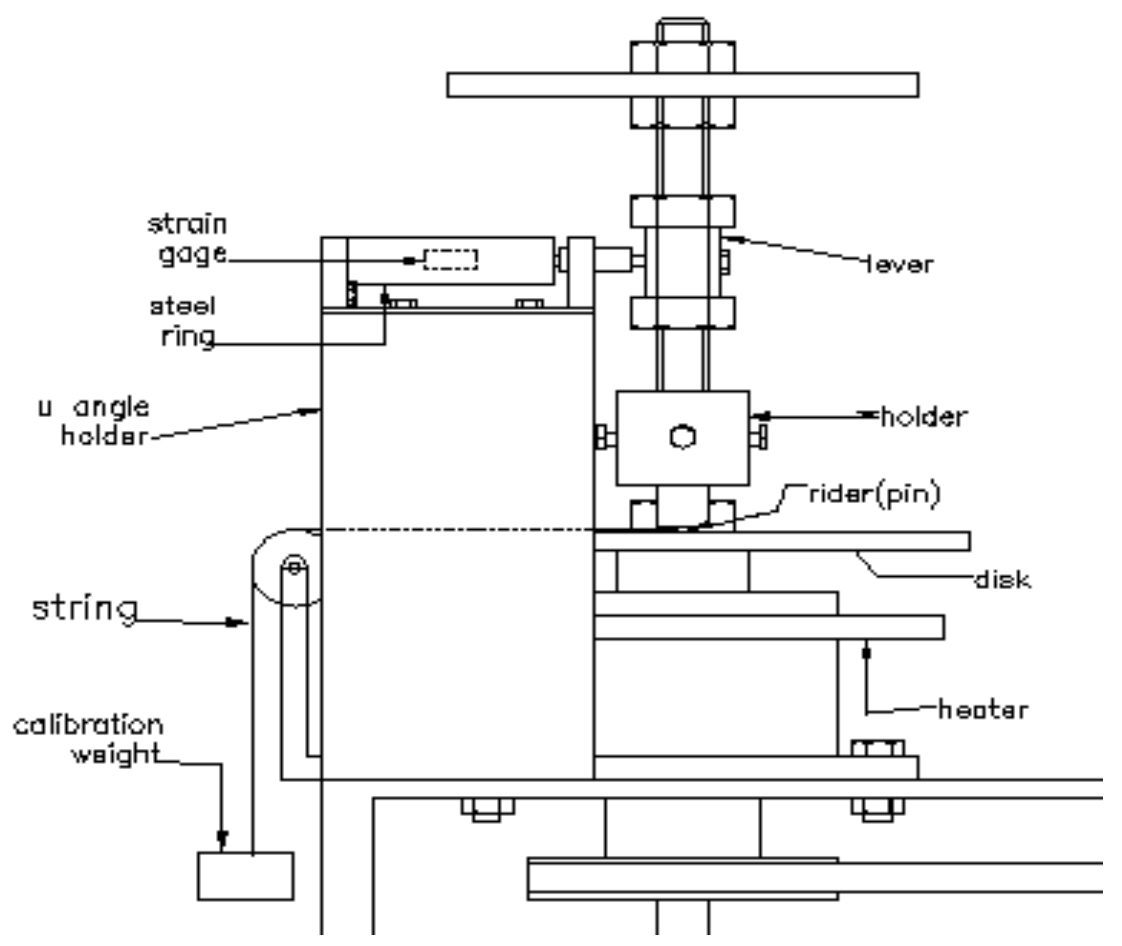

Figure 2. Four strain gages mounted on steel ring in addition to strain gage calibration system

1. a squirrel-cage type electrical motor (3-phase, and constant rotational speed of $940 \mathrm{rpm}$ ).

2. aluminum pulleys and a V-belt to transmit the speed.

3. a carbon steel rotating disc with a $24 \mathrm{~cm}$ diameter and a hardness of 35HRc and a surface finish of $0.8 \mu \mathrm{m}$.

4. a mechanism for loading the specimen which is drawn in detail in Fig. 1. Loading is applied by load weights representing normal force on pin and disc transmitted to the specimen by a lever system and holder. The fulcrum is $36 \mathrm{~cm}$ and $7 \mathrm{~cm}$ from disc center $3.7 \mathrm{~m} / \mathrm{sec}$ relative speed of pin and disc from the point of loading or $34 \mathrm{~cm}$ and $5 \mathrm{~cm}$ from disc center $2.7 \mathrm{~m} / \mathrm{sec}$ relative speed) as the load is applied directly to the holder.

5. four sensitive strain gages fixed on the inner and outer walls of a steel ring taken from TQ calibration apparatus (attachment set) of S6072-E-31 Techequipment strain meter shown in Fig. 2. (The system is fixed on the holder and the force is transmitted directly from the lever to the ring by a $5 \mathrm{~mm}$ diameter and of $3 \mathrm{~cm}$ long pin. The whole system was leveled and placed on a heavy steel table to minimize vibration).

\subsection{Wear Test}

The weight method was used to determine the wear rate of specimens. The specimens were weighted before and after the wear test with a sensitive balance type DENVER instrument Max-210gm with an accuracy of $0.0001 \mathrm{gm}$. The weight loss $\Delta \mathrm{W}$ was divided by the sliding distance and the wear rate was obtained by using the following equation (UNIDO, 1990).

Wear rate $=\Delta \mathrm{w} / \mathrm{S}_{\mathrm{D}}$

$\Delta \mathrm{w}=\mathrm{w}_{2}-\mathrm{w}_{1}$
$\mathrm{SD}=\mathrm{S}_{\mathrm{S}} \cdot \mathrm{t}$

Wear rate $(\mathrm{W} . \mathrm{R})=\Delta \mathrm{W} / \pi$ D.N.t

where:

$\begin{array}{ll}\mathrm{W} \cdot \mathrm{R} & =\text { wear rate }(\mathrm{gm} / \mathrm{cm}) \\ \mathrm{S}_{\mathrm{D}} & =\text { sliding distance }(\mathrm{m}) \\ \mathrm{S}_{\mathrm{S}} & =\text { linear sliding speed(m/sec.) } \\ \mathrm{D} & =\text { sliding circle diameter }(\mathrm{cm}) \\ \mathrm{SS} & =\text { sliding distance }(\mathrm{cm}) \\ \mathrm{t} & =\text { sliding time }(\mathrm{min}) \\ \mathrm{N} & =\text { steel disc speed }(\mathrm{rpm}) \\ \text { Hardness of } & =35 \mathrm{HRc} \\ \quad \text { steel disc } & \\ \text { Diameter of } & =10 \mathrm{~mm} \\ \quad \text { specimen } & \\ \text { Length of } & =20 \mathrm{~mm} \\ \text { specimen } & \end{array}$

\subsection{Measurement of Friction Coefficient}

Friction coefficient $(\mu)$ is found by dividing the frictional force (F) by the applied load (N) according to the equation as follows:

$$
\mu=F / N
$$

Frictional force is found by a specially designed steel ring taken from a calibration apparatus of a TQ strain meter mounted on a U-angle block, fixed on the bench and aligned with the left-side of the lever arm. The force is transmitted from the left side of the fulcrum lever to the 


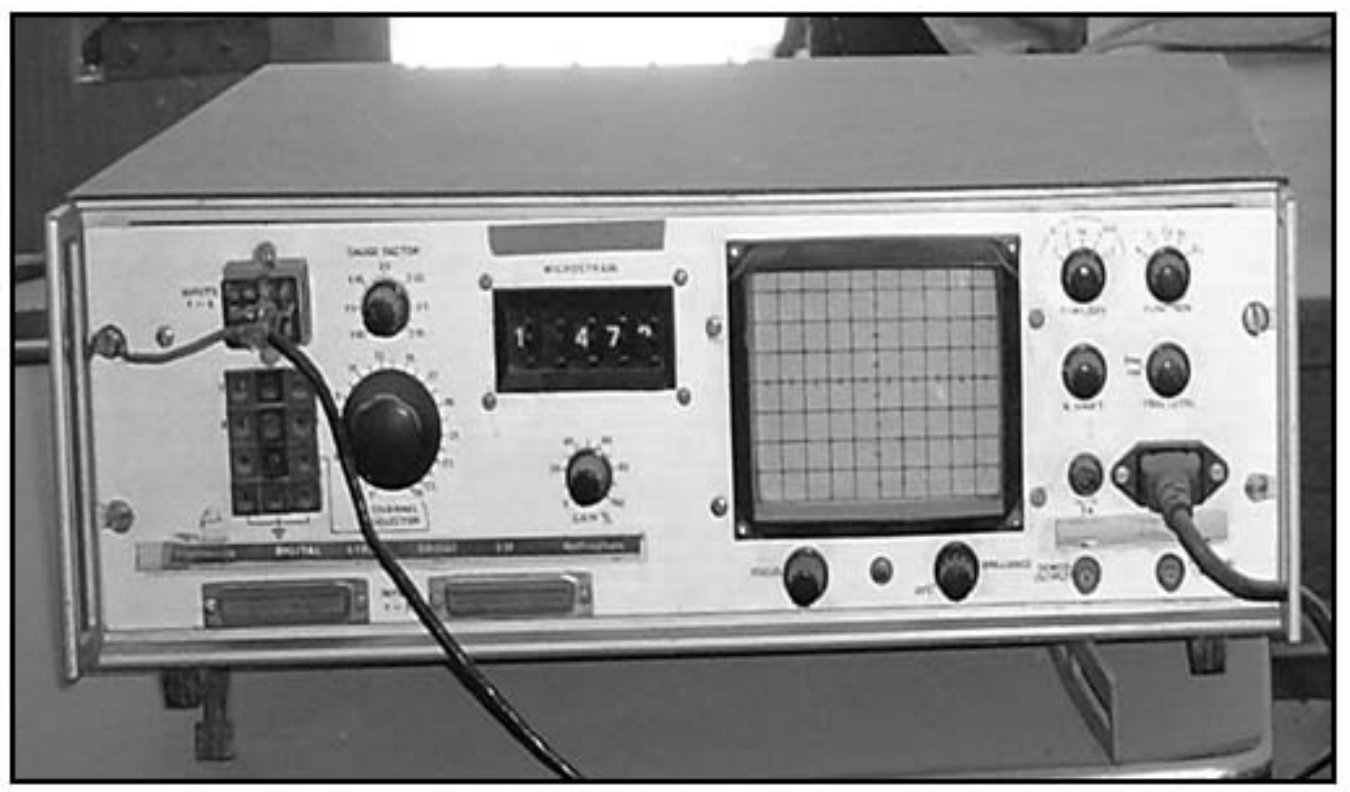

Figure 3. Micro strain meter aparatus used in this study

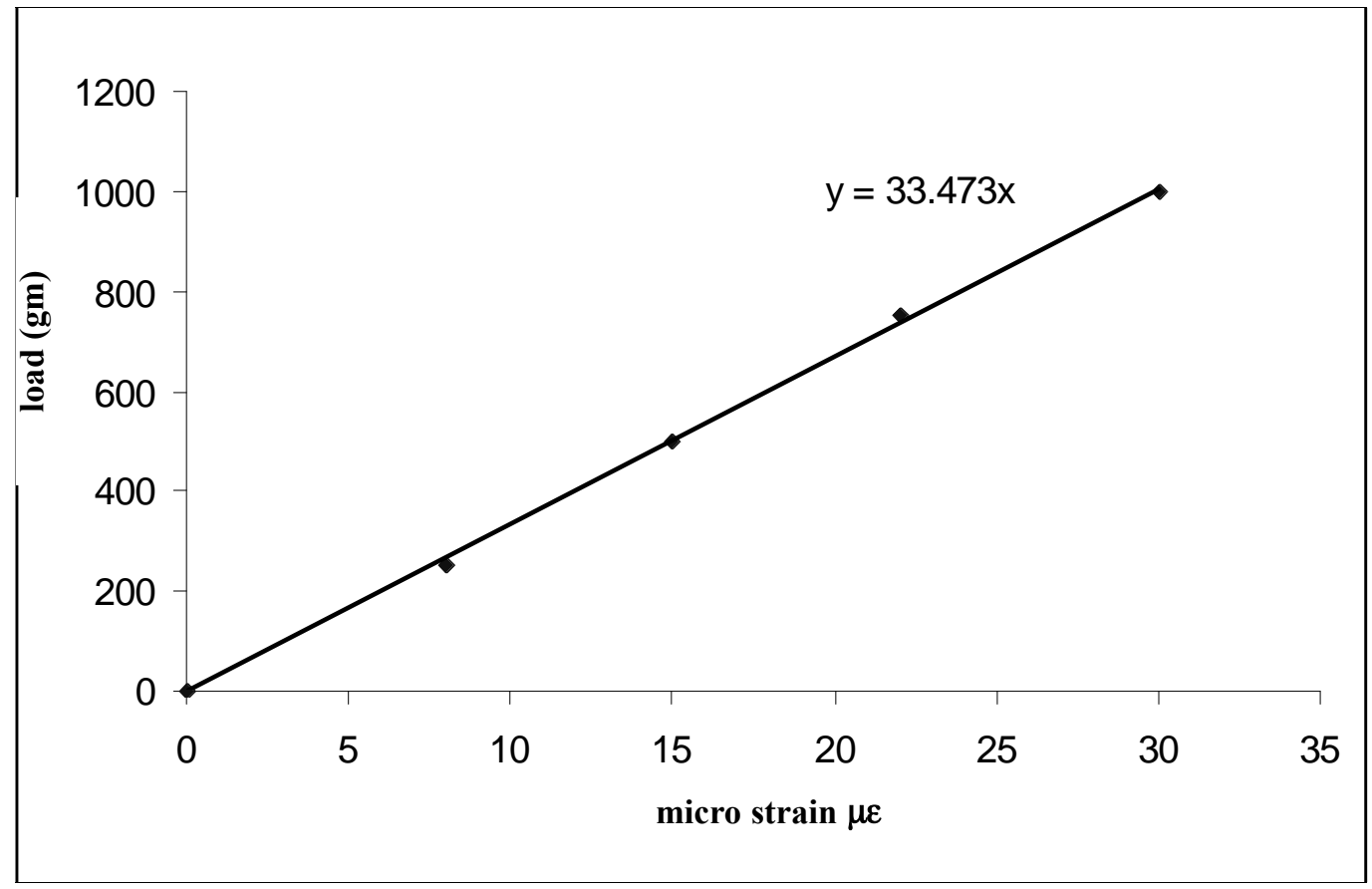

Figure 4. The calibration curve of load versus strain at a constant sliding time of $20 \mathrm{~min}$, sliding speed of $2.7 \mathrm{~m} / \mathrm{sec}$. and steel disc hardness of $35 \mathrm{HRc}$

ring by a $5 \mathrm{~mm}$ diameter and $3 \mathrm{~cm}$ long sliding rod. Two half bridges were formed on the inside and outside ring surfaces by means of four strain gauges with a gage factor of 2.065. These strain gages were then connected to a TQS6072 digital bridge strain meter as shown in Fig. 3. Before running the experiment, the digital strain micrometer display cathode ray screen was calibrated to record the micro-strain reading before and after running. The reading from the strain meter was taken and the calibration curve of load (force) versus strain was plotted in Fig. 4 at a constant sliding time (20 min) and sliding speed 2.7 $\mathrm{m} / \mathrm{sec}$ and the steel disc hardness was 35HRc.

\subsection{Measurement of Microhardness}

Small specimens of base alloy Al-12\%Si (alloy A) and of Cd-containing alloys alloys B, C \& D were prepared by turning processes in the dimensions of $12 \mathrm{~mm}$ in length and $10 \mathrm{~mm}$ in diameter. A wet grinding operation with water was done by using emery paper of SiC in the different grits (220, 320, 500, and 1000). Polishing was done to the specimens by using diamond paste of size $(1 \mu \mathrm{m})$ and special polishing cloth and lubricant. They were cleaned with water and alcohol and dried with hot air. Etching process was done to the specimens by using an etching solution which was composed of $(99 \% \mathrm{H} 2 \mathrm{O}+1 \% \mathrm{HF})$. 
Then the specimens were washed with water and alcohol and dried. The Vickers hardness test was carried out by using Vickers hardness tester type Einsingenbei U/M, Model Z323. A diamond indenter was forced into the surface of the specimen being tested under a static load of $300 \mathrm{mg}$ for 10 to $15 \mathrm{sec}$. Measurements of the indentation diagonal were made in 3 to 5 readings and the average hardness $\mathrm{HV}$ was found as shown in Table 1.

\section{Table 1. Hardness results of the studied alloys}

$\begin{array}{ccc}\begin{array}{c}\text { Specimen } \\ \text { No. }\end{array} & \text { Cd (wt\%) } & \text { HV }\left(\mathbf{K g} / \mathbf{m m}^{\mathbf{2}}\right) \\ \text { A } & \text { 0\% (base alloy) } & 70 \\ \text { B } & 1.0 & 85 \\ \text { C } & 2.0 & 97 \\ \text { D } & 3.0 & 103\end{array}$

\section{Results and Discussion}

\subsection{Microstructure Results}

Primary silicon has a cuboidal form which can be seen in the micrograph (Fig. 5a) of an alloy Al-12\%Si. The eutectic mixture, though, is non-lamellar in form and appears, in section, to consist of separate flakes of silicon (grey) and alpha Al-phase (white) (Basavakumar, et al. 2007). A coarse platelet of the crystals of the Al-Si eutectic phase was formed in the casting during solidification. These particles are brittle and tend to reduce the mechanical properties of the casting (Lidman, 2005 ). During the solidification of the cast Al-Si alloys in a primary $\alpha$-phase start to separate from the liquid. After nucleation when the temperature decreases the primary phase grows as solid crystals have a dendrite shape. On the polished surface two phases can be distinguished and the secondary arms of the dendrites cut on the sample phase clearly appear Zhang, et al. 2003). Figure (5b-5d) shows the microstructures of alloys B, C and D containing cadmium $1 \%, 2 \%$ \& $3 \%$ respectively. It is seen that the particles of $\mathrm{Cd}$ are distributed as small particles in the matrix and Al-Si eutectic phase, because it is probable that there is only an extremely small solubility of $\mathrm{Al}$ in solid $\mathrm{Cd}$ as indicated in Al-Cd phase diagram (Davis and Associates, 1982), see Fig. 6.

Modification and grain refinement in microstructure of Al-Si alloy have been achieved due to the presence of cadmium particles in the matrix of the eutectic phase. Fig. 7 indicates X-Ray diffraction analysis results of an alloy (Al-12\%Si-3\%Cd) and the presence of $\mathrm{Si}$ and $\mathrm{Al}$ phases in the microstructure of the alloy.

\subsection{Wear Results}

\subsubsection{Effect of Cd on Wear Rate}

The addition of $\mathrm{Cd}$ to the base alloy (Al-12 \%Si) leads to a decrease in wear rate as shown in Fig. 8. The wear behavior of base alloy (A) is mild wear (oxidative wear) at low loads 5-10 N, and when the load increases the wear rate increases and transforms to metallic wear at high loads 10-20 N. These results are in agreement with those of other researchers (Israa, 2005 and Jawdat, 2002).

In case of $\mathrm{Al}-12 \% \mathrm{Si}$ containing $1 \% \mathrm{Cd}$ (alloy $\mathrm{B}$ ) and $2 \% \mathrm{Cd}$ (alloy $\mathrm{C}$ ) respectively, Fig. 8 , it can be seen that the wear rate reaches maximum value at load $10 \mathrm{~N}$ and then decreases as the applied load increases to $20 \mathrm{~N}$. This is due to work-hardening of the matrix by plastic deformation which helped in reducing the extent of wear of the samples at high loads. During wear at high loads, the temperature increases appreciably, thus lowering the strength of the materials in contact and resulting in an increased contact area and coefficient of friction. The stronger grainrefined and modified alloys recorded the lowest wear rate. This is due to the presence of Cd phase as hard particles (the hardness of pure cadmium is 203MPa) distributed in matrix of (Al-Si), which reduces the contact area between the steel disc and the specimen surface in addition to the role of silicon phase which increases wear resistance. In Fig. 8 shows that the wear rate decreases to lower values as $\mathrm{Cd}$ addition increases to $3 \% \mathrm{Cd}$ in an $\mathrm{Al}-12 \% \mathrm{Si}$ alloy. These results are due to the increase in hardness of the alloy alloy D to $103 \mathrm{HV}$ in comparison with the base alloy (alloy A) which is $70 \mathrm{HV}$, see Table 1 which gives the hardness results of the studied alloys (See Table 1).

\subsubsection{Effect of Cd on Friction Coefficient}

When two surfaces slide together, most of the work done against friction is turned into heat. The resulting rise in temperature may modify the mechanical and metallurgical properties of the sliding surfaces, and it may make them oxidize or even melt. All these things influence the wear rate and friction coefficient.

In order to minimize friction forces we must use lubricants. These contaminate the surface preventing adhesive contact and obviously lowering the coefficient of friction ( $\mu$ ) (Mikell Groover, 1999).

In this work, friction coefficient can be reduced, under dry sliding conditions by increasing the surface hardness of the alloy (A1-12\%Si) through the addition of cadmium to a matrix of eutectic phase (Al-Si). Figure 9 shows the relationship between the coefficient of friction $(\mu)$ and sliding time at a constant load of $20 \mathrm{~N}$ for different alloys (A, B, C \& D). In the first sliding time the $\mu$ increases with time until it reaches a steady state and then continuing for longer periods (20 minutes or more). This is due to the presence of cuboids or hard cadmium particles distributed in the matrix which resists the large applied forces normal to the surface and hence separate the asperity tips very effectively, while the two surface layers can shear over each other quite easily. This can reduce the coefficient of friction $(\mu)$. It was found that as the $\mathrm{Cd} \%$ increases the grains becomes smaller and finer. The stronger grain-refined and modified alloys recorded the lowest coefficient of friction. These results are similar to those of references (Basavakumar, et al. 2007 and ASM Materials, 2002).

\subsubsection{Worn Surface Results}

There are two main types of wear abrasive wear and adhesive wear. The present work studied the former one. 
Al-12\% Si alloy

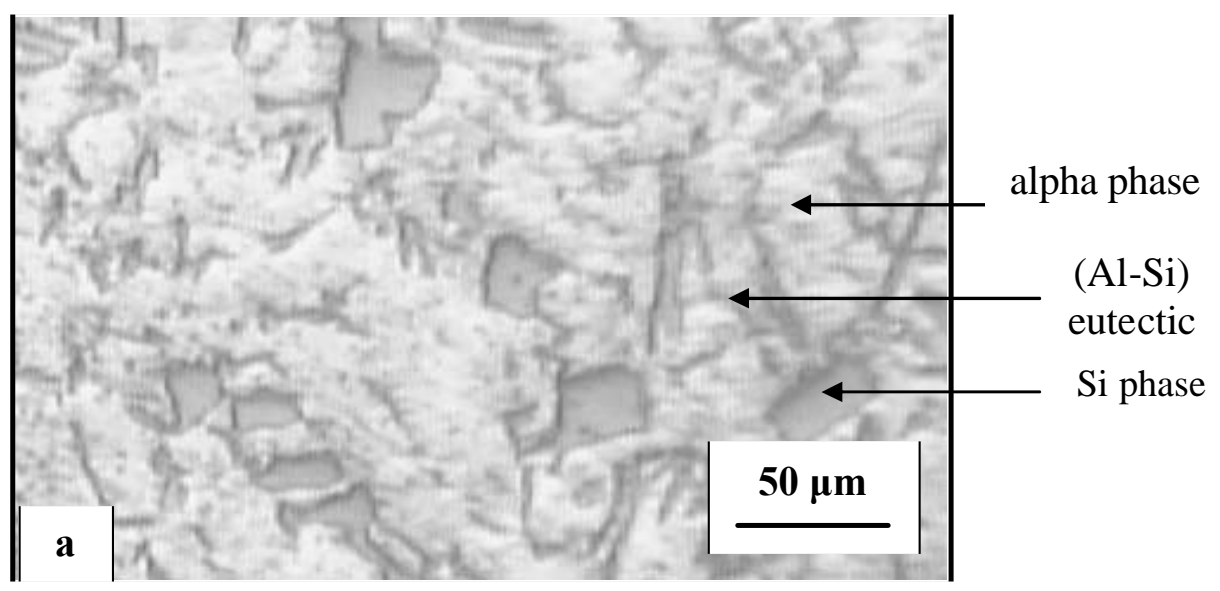

Al-12\% Si alloy $1 \% \mathrm{Cd}$

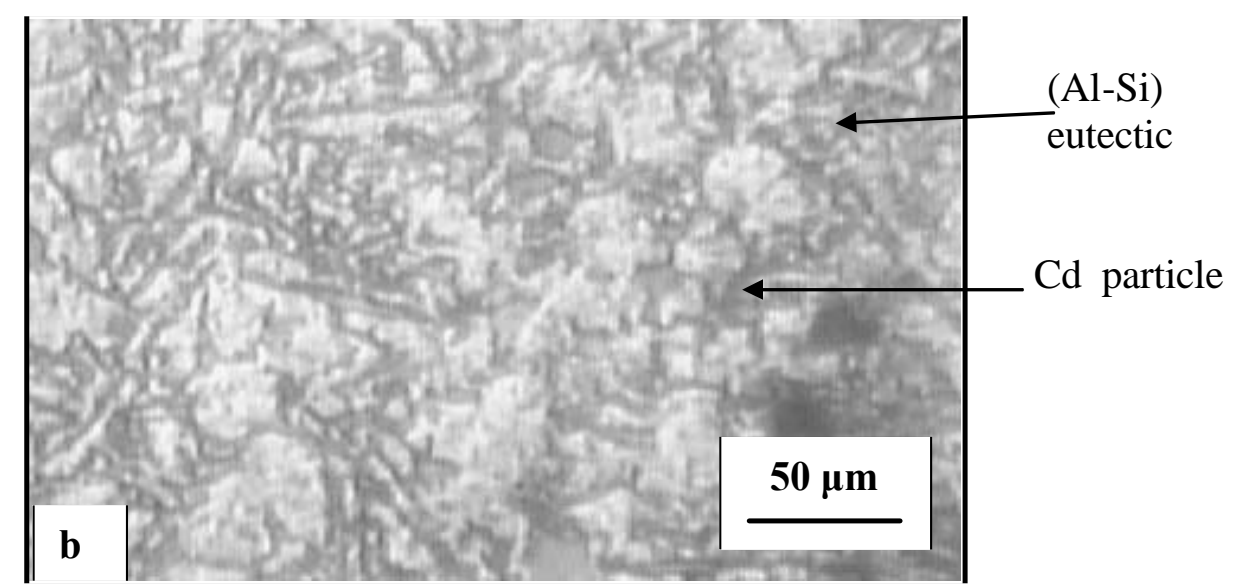

Al-12\% Si alloy $2 \% \mathrm{Cd}$



Al-12\% Si alloy $3 \%$ Cd

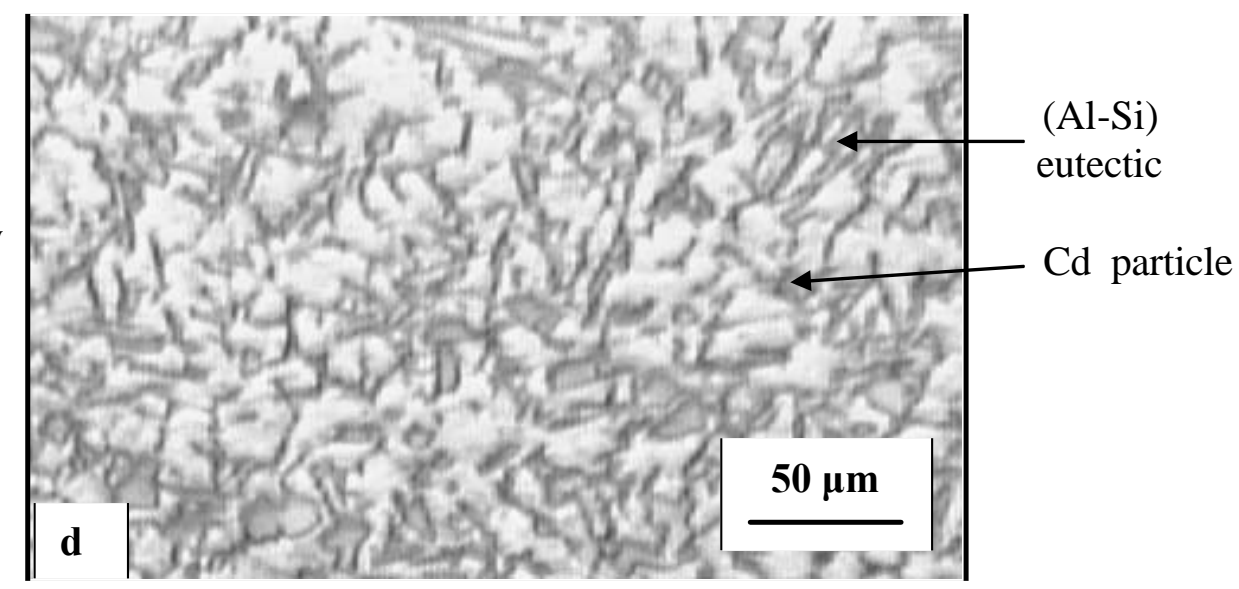

Figure 5. The microstructures of the studied alloys (as cast) 


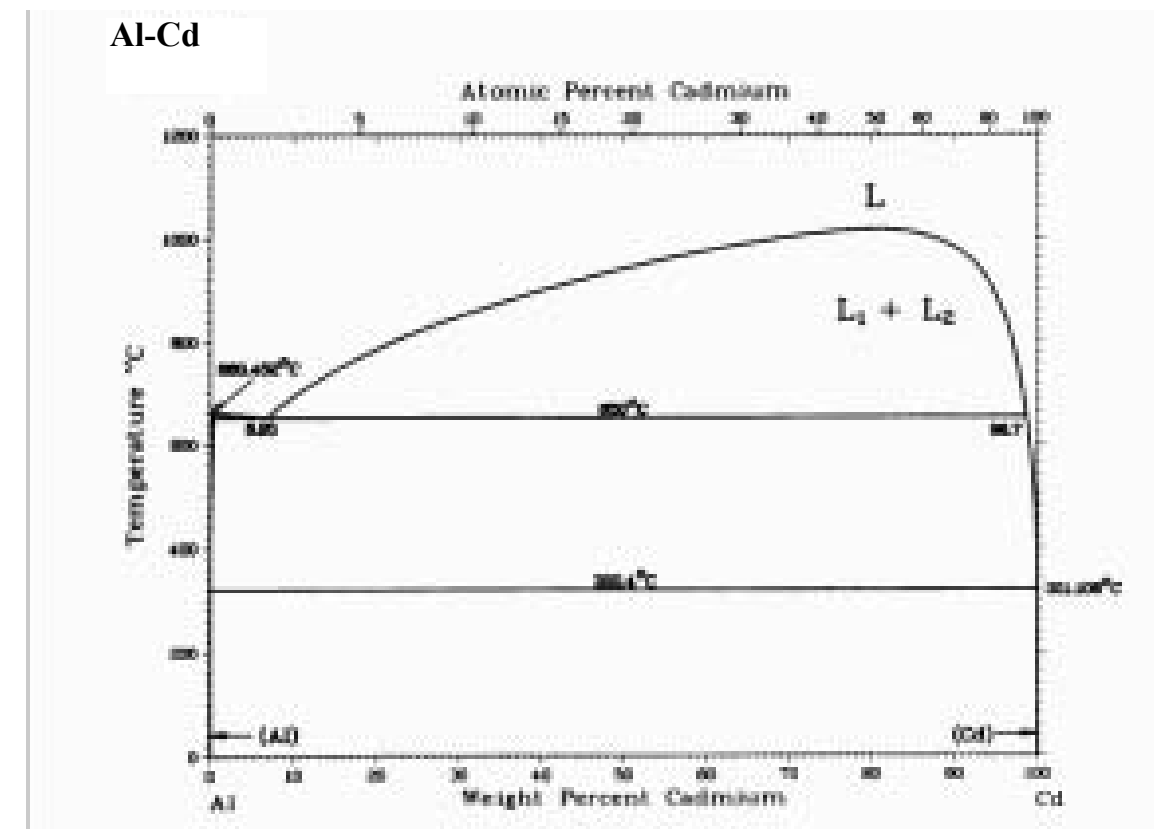

Figure 6. Phase diagram of Al-Cd alloys (Davis, J.R. and Associates, 1982)

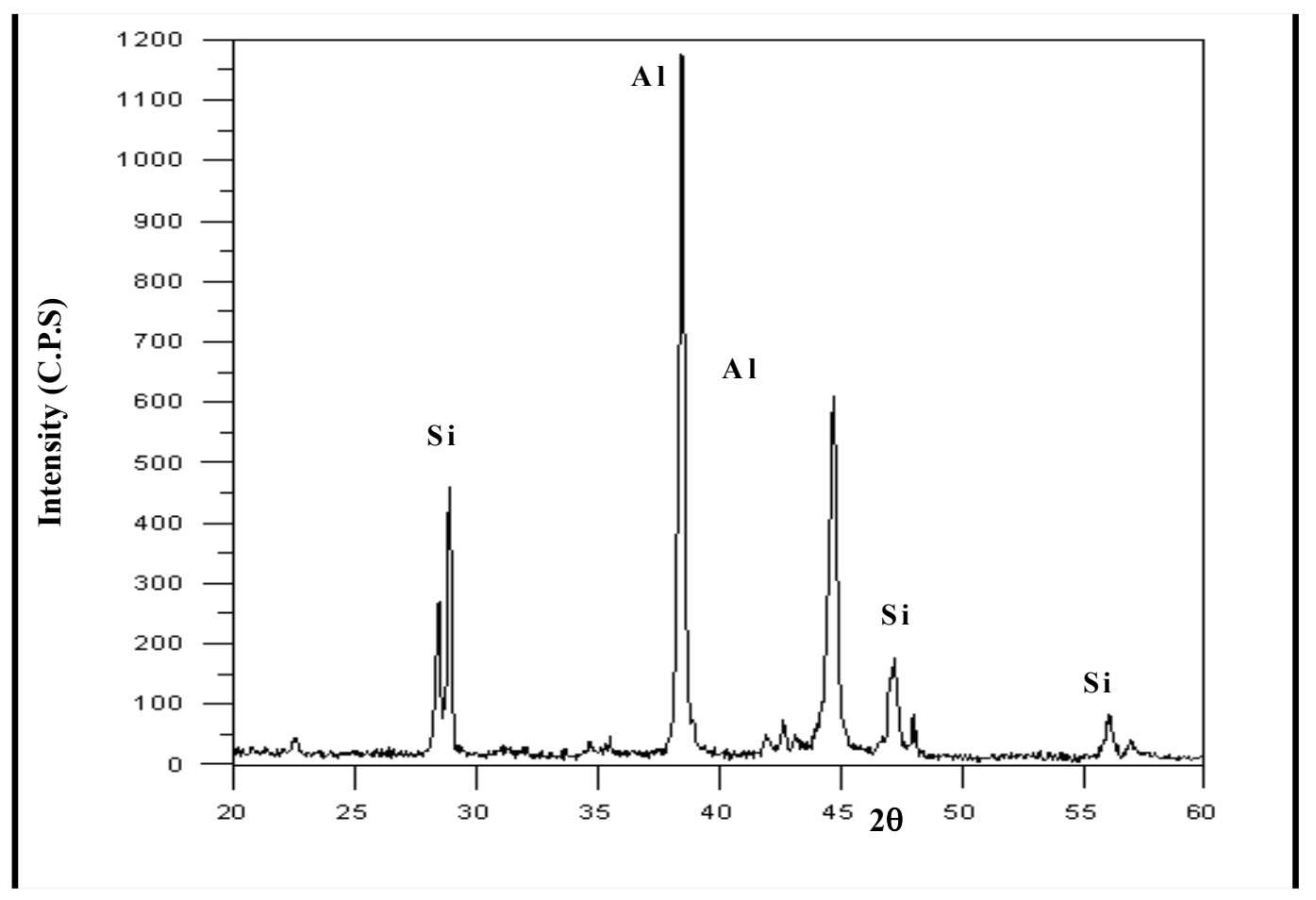

Figure 7. XRD results of an alloy $(\mathrm{Al}-12 \% \mathrm{Si}-3 \% \mathrm{Cd})$

Adhesive wear is often called frictional wear since it arises from the same basic mechanism of friction that comes from welding and subsequent shearing of minute surface asperities. When two nominally flat surfaces, no matter how smooth are brought into contact, they will only touch at relatively few isolated points. When sliding occurs these welds are sheared. When operating under heavy loads (or high speeds), the wear debris will appear as large mainly metallic particles (severe wear). On the other hand operation under light loads (or low speeds) will produce fine oxide wear debris (mild wear) (Ashby and Jones, 1980).

Figures 10a-10d show micrographs of the worn surfaces of specimens (A, B, C \& D) at an applied load of $20 \mathrm{~N}$ during wear test. 


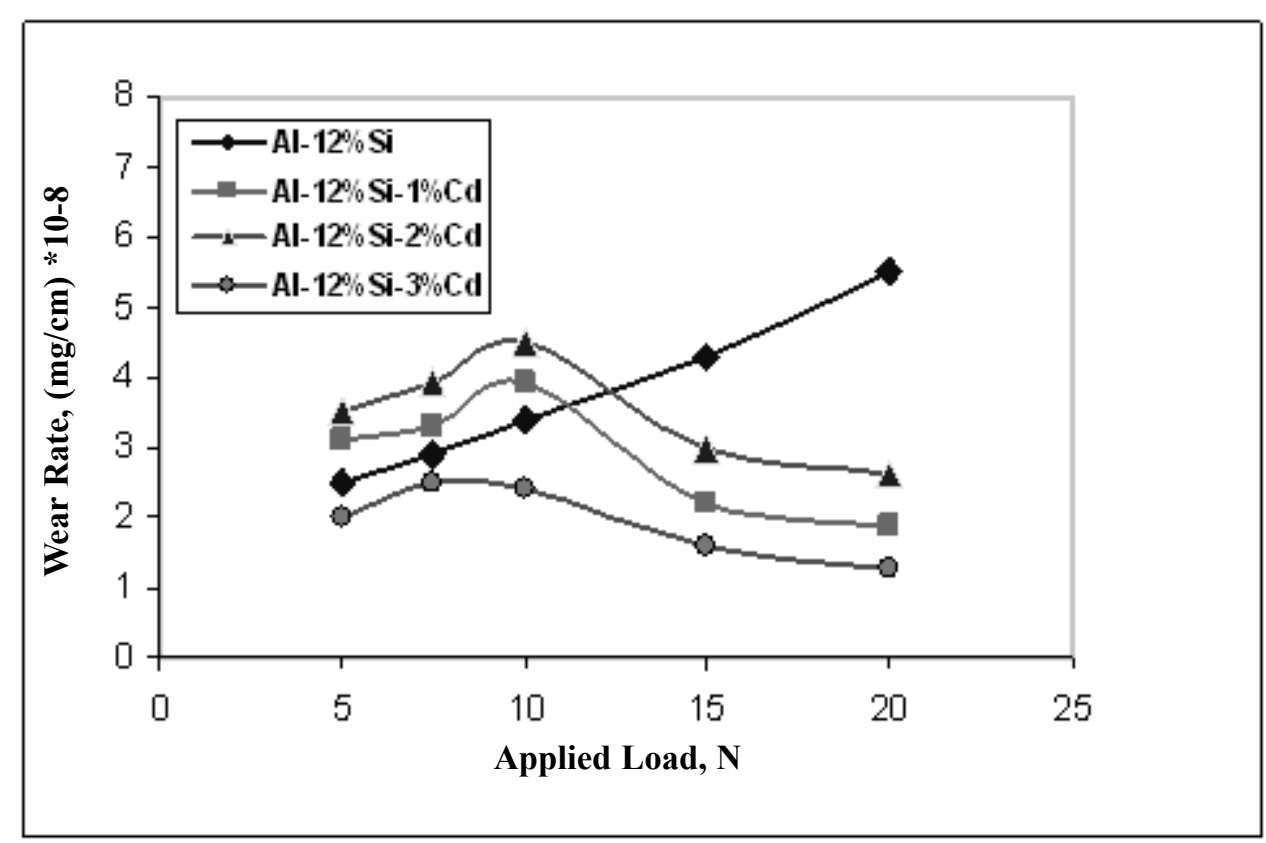

Figure 8. The effect of applied load on wear rate of different alloys at a sliding speed of $2.7 \mathrm{~m} / \mathrm{sec}$, sliding time of $20 \mathrm{~min}$ and steel disc hardness of $35 \mathrm{HRc}$

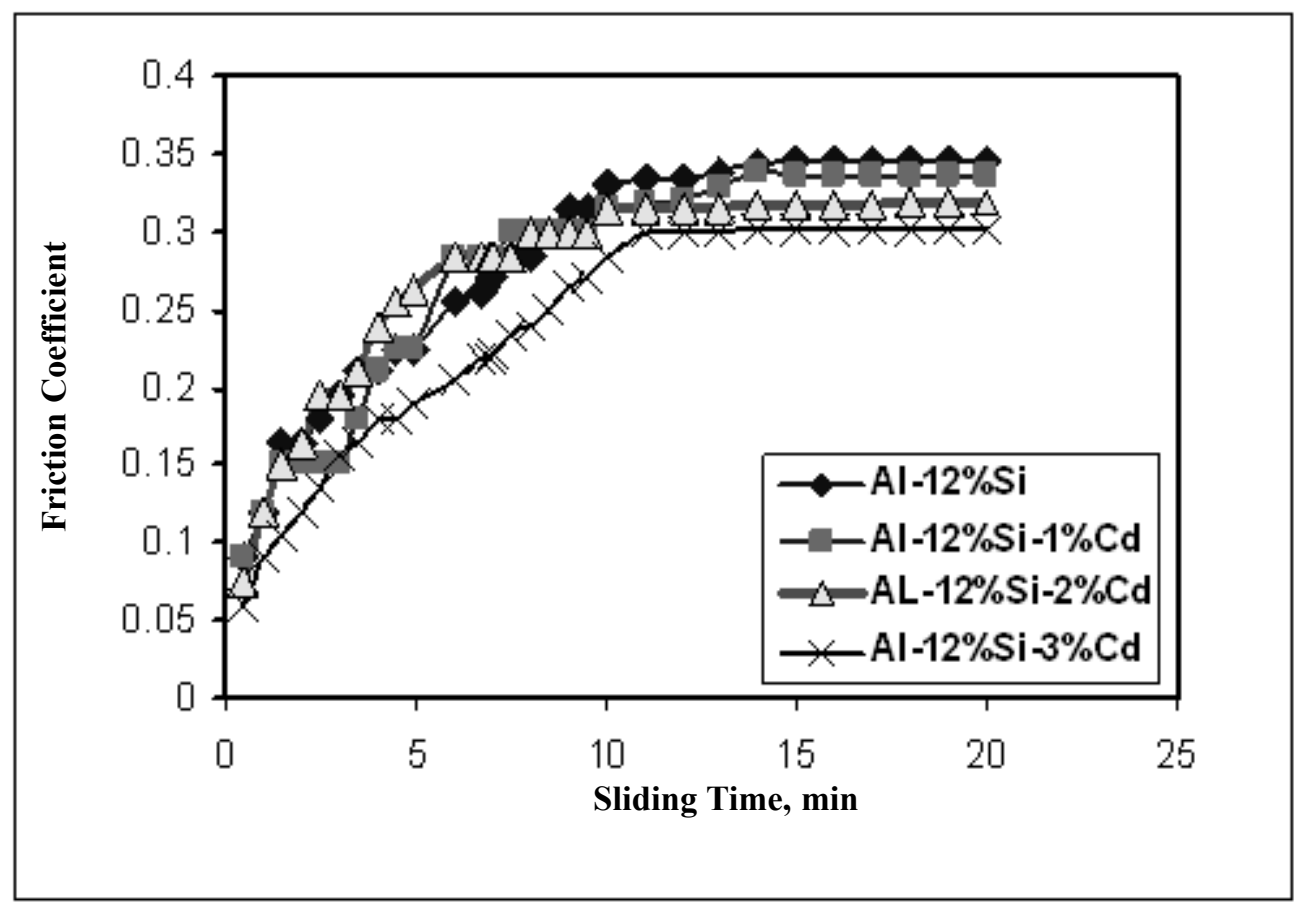

Figure 9. The effect of cadmium adding on friction coefficient $(\mu)$ of different alloys at a applied load of $20 \mathrm{~N}$ and sliding speed of $2.7 \mathrm{~m} / \mathrm{sec}$

The worn or damaged surface shows continuous grooves and cracking of a long wear track. In some places, some plastic deformation, together with presences of fine oxides debris particles are also observed in case of base alloy $\mathrm{Al}-12 \% \mathrm{Si}$. While it is seen as smooth and with glassy finish and faint wear lines in the direction of sliding on worn surfaces, this indicates that a mild abrasion wear mode is present in case of $\mathrm{Al}-12 \% \mathrm{Si}$ alloys containing cadmium especially alloy D.

\section{Conclusions}

1. Modification and grain refinement in the microstructure of Al-Si alloy have been achieved by the presence of cadmium particles in the alloy matrix.

2. The wear behavior of base alloy A1-12\%Si changes from mild wear (oxidative wear) at low loads 5-10 N to metallic wear at high loads $10-20 \mathrm{~N}$.

3. The cadmium added to alloy $\mathrm{Al}-12 \% \mathrm{Si}$ changes the wear behavior at higher loads than 5-10 N. 


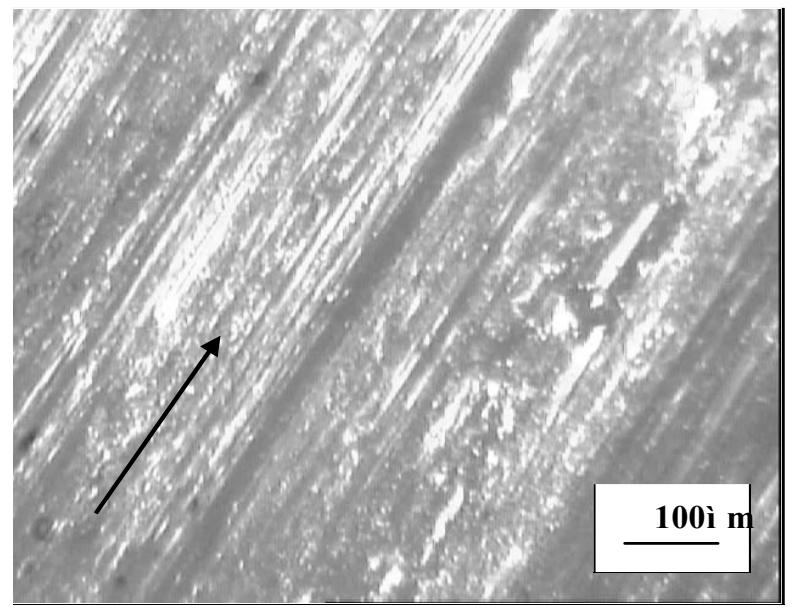

(a) $\mathrm{Al}-12 \% \mathrm{Si}$ (Base alloy)

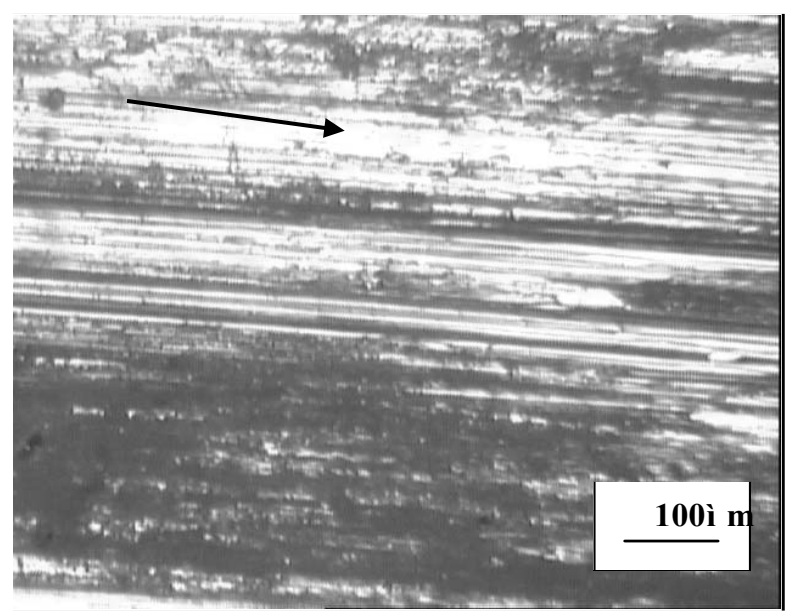

(c) $\mathrm{Sl}-12 \% \mathrm{Si}-2 \% \mathrm{Cd}$

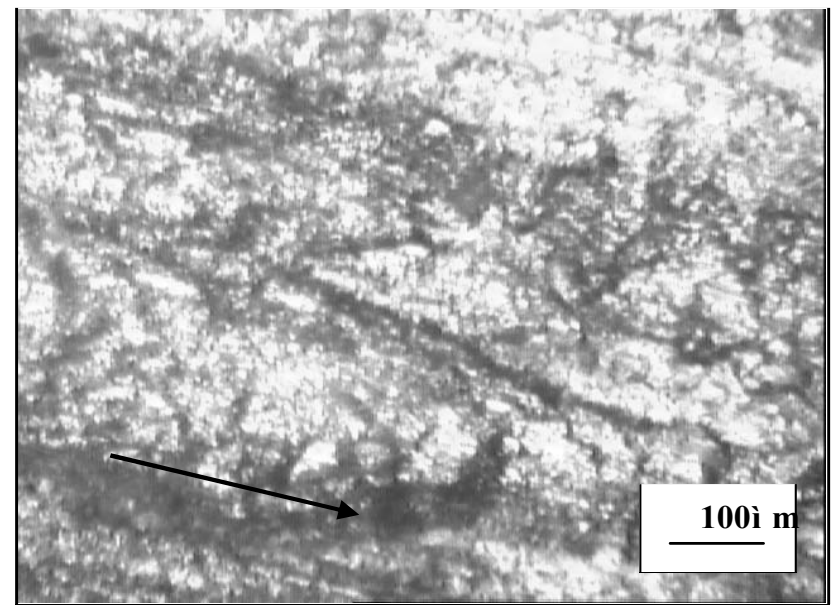

(b) $\mathrm{Al}-12 \% \mathrm{Si}-1 \% \mathrm{Cd}$

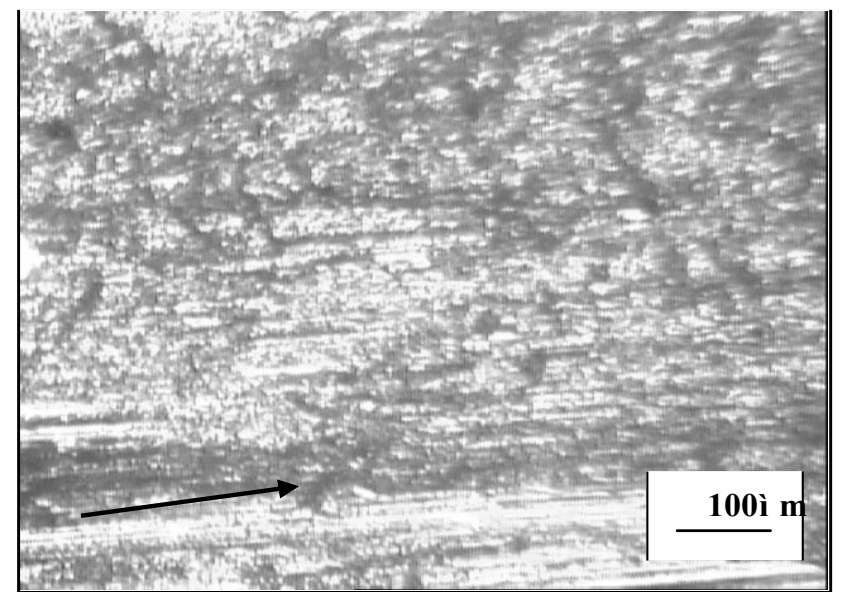

(d) $\mathrm{Al}-12 \% \mathrm{Si}-3 \% \mathrm{Cd}$

Figure 10. Micrographs of the worn surfaces of different alloys at a applied load of $20 \mathrm{~N}$, sliding speed of $2.7 \mathrm{~m} / \mathrm{sec}$ and steel disc har dness of $35 \mathrm{HRc}$ sliding direction

4. The alloy A1-12 \% Si containing 3\% Cd shows the highest wear resistance in comparison with other alloys at a high load $20 \mathrm{~N}$.

5. The cadmium added to alloy Al-12 \% Si reduces the friction coefficient at high loads.

6. The addition of cadmium at different ratios leads to an increase in the hardness of the aluminum silicon based alloy.

\section{References}

Abbas, M.K. and Ibrahim, E.K., 2003, "Effect of Copper and Magnesium Adding on Wear Behavior of (Al-Si) Alloy," Engineering and Technology Journal, University of Technology, Baghdad - Iraq, Vol. 22(1), pp. 37-44.
Ashby, M.F. and Jones, D.R.H., 1980, "Engineering Materials, An Introduction to Their Properties and Application," Pergamon Press Ltd, Headington HillHall, Oxford, England.

Askwith T.C., 1980, "The Basic Mechanisms of Wear," Surfacing Journal, Vol. 11(4), pp. 2-5.

ASM Materials, 2002, "Bismuth Added to Al-Si Alloy Enables Low Friction," Advanced Materials Progress. ASTM., 1989, "Metals Test Method and Analytical Procedure," Vol. 05.02.

Basavakumar, K.G., Mukunda, P.G. and Chakraborty, M., 2007, "Influence of Melt Treatments on Sliding Wear Behavior of $\mathrm{Al}-7 \mathrm{Si}$ and $\mathrm{Al}-7 \mathrm{Si}-2.5 \mathrm{Cu}$ Cast Alloys," Journal of Material Science, Vol. 42, pp. 7882-7893.

Bolten, W., 1998, "Engineering Materials Technology," Butterworth's, $3^{\text {rd }}$ ed. 
Dana, E.C.H., 2001, "Information From Clevite Engine Parts Division, "Engine Bearing Fundamentals, Part 6 Bimetals," pp. 1-2.

Davis, J.R. and Associates, 1982, "ASM International Handbook Committee," by A.J. McAlister, p. 545. http://books.geogle.com

Israa, A.K., 2005, "The Effect of Lead Addition on The Wear Resistance of Al-16\%Si Alloy Under Dry Sliding," Journal of Engineering and Technology University of Technology, Baghdad, Vol.24(1), pp. 56-64.

Jawdat, A.G., 2002, "Effect of Some Additions on Wear Resistance and Mechanical Properties of (Al-8\% Si)," M.Sc. Thesis, University of Technology, Baghdad , Iraq.

Lidman, W.G., "Aluminum Master Alloys and Additives, The Magic Ingredients," The Aluminum Association, Association's, website at www.aluminum.org.

Mikell, P. Groover, 1999, "Fundamentals of Modern
Manufacturing Materials Processes and Systems," John, Wiley \& Sons, Inc.

Mustafa, S.F., 1995, "Wear and Wear Mechanisms of Al22\%Si -203 Composite," Wear, Vol. 185, p. 189.

Sreeja Kumar, S.S.., Pillai, R.M., Nogita, K., Dahle, A.K. and Pai, B.C., 2006, "A Influence of Calcium on the Microstructure and Properties of an Al-7\%Si0.3\%Mg- xFe Alloy," Metallurgical and Materials Transaction A, Vol.37A, p. 2581.

Stan Grainger., 1994, "Engineering Coatings Design and Application," Woodhead Publishing Ltd.

UNIDO., 1990, "Advances in Material Tech," Monitor Vienna International Center, Austria, pp. 9-11.

Zhang, Z., Garro, M. and Tagliano, C., 2003, "Dendrite Arm Spacing in Aluminum Alloy Cylinder Heads Produced by Gravity Semi- Permanent Mold," Metallurgical Science and Technology, A Journal Published by Teksid Aluminum Twice A year, Vol.21(1), pp. 1-9. 